\title{
Role of Heat Treatment on Atomic Order and Ordering Domains in $\mathrm{Ni}_{45} \mathrm{Co}_{5} \mathrm{Mn}_{36.6} \mathrm{In}_{13.4}$ Ribbons
}

\author{
Yan Feng ${ }^{1, *(\mathbb{D}, \text { Xueman Wan }}{ }^{2}$, Xiaohai Bian ${ }^{1}$, Yanling $\mathrm{Ai}^{1}$ and Haibo Wang ${ }^{3}$ \\ 1 State Key Laboratory of Solidification Processing, Northwestern Polytechnical University, \\ Xi'an 710072, China; bianxiaohi@163.com (X.B.); ai_yanling@nwpu.edu.cn (Y.A.) \\ 2 National Key Laboratory of Science and Technology on Space Microwave, China Academy of Space \\ Technology Xi'an, Xi'an 710100, China; x.m.wan@mail.nwpu.edu.cn \\ 3 College of Physics and Electronic Engineering, Taizhou University, Taizhou 318000, China; \\ hb_wang_hit@163.com \\ * Correspondence: yanfeng@nwpu.edu.cn
}

Citation: Feng, Y.; Wan, X.; Bian, X.; $\mathrm{Ai}, \mathrm{Y}$.; Wang, H. Role of Heat Treatment on Atomic Order and Ordering Domains in

$\mathrm{Ni}_{45} \mathrm{Co}_{5} \mathrm{Mn}_{36.6} \mathrm{In}_{13.4}$ Ribbons. Metals 2021, 11, 1472. https://doi.org/ $10.3390 /$ met11091472

Academic Editor: Martin Heilmaier

Received: 27 July 2021

Accepted: 9 September 2021

Published: 16 September 2021

Publisher's Note: MDPI stays neutral with regard to jurisdictional claims in published maps and institutional affiliations.

\begin{abstract}
The effects of cooling rate and annealed temperature on the state of atomic order and microstructure of $\mathrm{L}_{2}$ domains of $\mathrm{Ni}_{45} \mathrm{Co}_{5} \mathrm{Mn}_{36.6} \mathrm{In}_{13.4}$ ribbons are investigated comprehensively. The state of atomic order is quantitatively studied by in situ X-ray diffraction (XRD), and the microstructure of ordered domains is revealed by transmission electron microscopy (TEM). As-spun ribbons show B2 structure of low atomic order, exhibiting the dispersive L $2{ }_{1}$ domains' morphology. By applying heat treatment around the order-disorder transition temperature followed by furnace cooling or quenching into water, respectively, we found the strong dependence of ordered domains on cooling rates. Furnace cooling samples show L2 1 domains with small sized antiphase boundary, revealing a high degree of atomic order, while quenching hinders the formation of ordered domains. Annealing above the order-disorder transition temperature followed by quenching preserves the disordered atomic state with the mixture of $\mathrm{L} 2{ }_{1}$ structure in B2 matrix.
\end{abstract}

Keywords: intermetallics; heat treatment; domain morphology; phase transition; transmission electron microscopy

\section{Introduction}

Ni-Mn-X (X = In, Sn, Sb) ferromagnetic shape memory alloys (FSMAs) are a kind of Heusler alloys [1], which have been extensively investigated for a few decades due to their excellent physical properties such as long-range magnetic ordering [2], giant magnetoresistance [3,4], magnetocaloric effects [5] and a perfect shape memory effect induced by the magnetic field in Co doped Ni-Mn-X Heusler alloys [6]. The addition of Co to Ni-Mn-In alloys has enhanced the magnetism of the austenite and results in an increase in magnetization change $(\Delta M)$ at martensitic transformation [7]. In these quaternary alloys, the entropy change $(\Delta S)$ at the transformation and the physical properties strongly vary with atomic order [8,9]. The typical stoichiometric Heusler composition is $X_{2} Y Z$, showing the $\mathrm{L} 2{ }_{1}$-ordered crystal structure (space group $\mathrm{Fm} \overline{3} \mathrm{~m}$ ) with next-nearest-neighbor atomic order indicted by (111), (311) and (331) superlattice reflections [10]. This face-centered (fcc) superlattice structure consists of eight body-centered cubic (bcc) sublattices. In each unit, the $\mathrm{X}$ atoms locate at the cubic sublattice, while the body-centered position is regularly occupied by $Y$ and $Z$ atoms, composing a $Y Z$ sublattice $[10,11]$. However, if $Y$ and $Z$ atoms are randomly distributed at body-centered positions, a disorder in $\mathrm{YZ}$ sublattice appears, generating a CsCl-type B2-ordered structure (space group $\operatorname{Pm} \overline{3} \mathrm{~m}$ ) with next-neighbor atomic order [11,12]. Moreover, the $\mathrm{L}_{1}$ ordering parameter $\left(S_{L 21}\right)$ of the parent phase is 
estimated by the ratio of (111) superlattice reflection intensity and fundamental reflection from XRD diffraction patterns [13]:

$$
S_{L 21}=\left[\frac{I_{(111)}^{S} / I_{(220)}^{f}}{I_{O(111)}^{S} / I_{O(220)}^{f}}\right]^{1 / 2}
$$

where $I_{(111)}^{S} / I_{(220)}^{f}$ is an experimentally obtained intensity ratio, $I_{O(111)}^{S} / I_{O(220)}^{f}$ is the perfect-ordered L2 $2_{1}$ structure intensity ratio. By applying heat treatment to obtain the L2 1 phase, the evolution of atomic order produces the antiphase boundary (APB), which are the $\mathrm{B} 2$ regions $[14,15]$. APB is the planar defect in which the atomic order is close to B2 structure and is adjacent to the highly-ordered $\mathrm{L} 2{ }_{1}$ domains [16]. It is reported that the $\mathrm{L} 2_{1}$ domains and $\mathrm{B} 2$ regions formed in solution treated $\mathrm{Ni}-(\mathrm{Co})-\mathrm{Mn}$-In alloys observed by dark-field TEM images demonstrate unique microstructural morphology, and this microstructure defect influences martensitic transformation characteristics [17].

Ribbons produced by melt spinning techniques show homogeneous chemical composition and preferred orientated columnar crystal [18]. However, the long-range atomic diffusion has been hindered during the non-equilibrium solidification process, of which the cooling rate is on the order of $10^{4}-10^{6} \mathrm{~K} / \mathrm{s}$ [19]. The disordered atom occupancies of as-spun ribbons can be modified by ordering transition through annealing with different temperatures and applying different cooling rates [20]. The morphology of $\mathrm{L} 2{ }_{1}$ domains is also correlated with atomic order. Therefore, in this paper, we have studied the influence of annealed temperature, cooling rates on ordering transition and the mechanism of atomic order state on the $\mathrm{L} 2{ }_{1}$ domains' morphology.

\section{Materials and Methods}

The $\mathrm{Ni}_{45} \mathrm{Co}_{5} \mathrm{Mn}_{36.6} \mathrm{In}_{13.4}$ as-cast ingots prepared by arc melting in an argon atmosphere were electrical-discharge machined into small bulks for melt spinning and homogenized treatment. A part of the as-cast bulks was melted by electromagnetic induction and then ejected onto water cooling copper wheel with rotating linear speed of $15 \mathrm{~m} / \mathrm{s}$. The remaining bulks were annealed at $1173 \mathrm{~K}$ for $12 \mathrm{~h}$, followed by quenching in ice water. Then, half of the annealed bulks were ground into powders and annealed at $1173 \mathrm{~K}$ for $8 \mathrm{~h}$ with furnace cooling to obtain equilibrium state, while half of the annealed bulks were annealed at $850 \mathrm{~K}$ for $80 \mathrm{~h}$ with furnace cooling further in order to obtain a fully ordered L2 1 structure. The state of atomic order was modulated by annealing with two different cooling rates in the ribbons. Thus, as-spun ribbons were annealed for $2 \mathrm{~h}$ at $700 \mathrm{~K}, 800 \mathrm{~K}, 900 \mathrm{~K}, 1000 \mathrm{~K}$ and $1100 \mathrm{~K}$ followed by ice-water quenching (QW) and furnace cooling (FC), respectively. The order-disorder transition temperature $\left(T_{t}^{B 2 / L 2_{1}}\right)$ was determined by Netzsch STA 449 F5 Jupiter ${ }^{\circledR}$ Differential Scanning Calorimetry (DSC, NETZSCH204F1, NETZSCH-Gerätebau $\mathrm{GmbH}$, Selb, Germany), and the heating/cooling rate was $20 \mathrm{~K} / \mathrm{min}$. In addition, in situ XRD experiment (D8 advance, Bruker, Bremen, Germany) was performed on Ni-(Co)$\mathrm{Mn}$-In powders made from as-cast ribbons with $\mathrm{Cu} \mathrm{K} \alpha$ radiation in high vacuum. It was conducted at a heating rate of $10 \mathrm{~K} / \mathrm{min}$ and scanning speed of $3^{\circ} / \mathrm{min}$ with a $0.02^{\circ}$ stepsize and temperature ranged from 700 to $1100 \mathrm{~K}$. In order to determine the atomic order state of the FC and QW ribbons, XRD (X'Pert PRO MPD, Malvern Panalytical, Almelo, the Netherlands) tests were carried out at room temperature (RT) with a scanning speed of $5^{\circ} / \mathrm{min}$ and step size of $0.03^{\circ}$. Observation of $\mathrm{L} 2{ }_{1}$ domains was observed by using Transmission Electron Microscopy (TEM, Tecnai F30G', FEI, Hillsboro, OR, USA). The TEM samples were prepared by using a twin-jet electropolishing unit operated at $15 \mathrm{~V}$ and $100 \mathrm{~mA}$ in the temperature range of $283-288 \mathrm{~K}$, with a solution of $70 \mathrm{vol} \%$ ethanol and $30 \mathrm{vol} \%$ nitric acid. 


\section{Results and Discussion}

\subsection{Structure Evolution}

The in situ XRD analysis of $\mathrm{Ni}_{45} \mathrm{Co}_{5} \mathrm{Mn}_{36.6} \mathrm{In}_{13.4}$ powder in the heating process is shown in Figure 1a, and the (111) reflections of the fully ordered bulk, which is subjected to long time annealing, is shown in the inset. The disappearance of (111) reflections at $1000 \mathrm{~K}$ and $1100 \mathrm{~K}$ indicates that the order-disorder transition is between $900 \mathrm{~K}$ and $1000 \mathrm{~K}$. DSC heating curve of as-spun ribbons annealed at $1173 \mathrm{~K}$ for $1 \mathrm{~h}$ is shown in Figure $1 \mathrm{~b}$. Comparing it with the in situ XRD analysis, the exothermic peak detected at $950 \mathrm{~K}$ corresponds to the transition from $B 2$ to $L 2_{1}$ phase $\left(T_{t}^{B 2 / L 2_{1}}\right)$. This is consistent with the previous results of $T_{t}^{B 2 / L 2_{1}}$, ranged between $800 \mathrm{~K}$ and $1100 \mathrm{~K}$ in Ni-Mn-In alloys [21]. Table 1 lists the degree of $\mathrm{L} 2_{1}$ atomic order in in situ heating processes of Ni-Co-Mn-In alloys, which is calculated from Equation (1). $\mathrm{S}_{\mathrm{L} 21}$ at $700 \mathrm{~K}, 800 \mathrm{~K}$ and $900 \mathrm{~K}$ increases with the increase in temperature, which is due to a thermally induced ordering transition from B2 structure to $\mathrm{L} 2{ }_{1}$ highly-ordered structure. Moreover, there is no $\mathrm{S}_{\mathrm{L} 21}$ value at $1000 \mathrm{~K}$ and $1100 \mathrm{~K}$ due to the disappearance of (111) reflections in XRD, suggesting that the atomic diffusion inclines to form short-range atomic order (B2 structure), as the heating temperature is higher than $T_{t}^{B 2 / L 2_{1}}$. Figure $1 \mathrm{c}, \mathrm{d}$ are XRD analyses of (111) reflections of Ni-(Co)-Mn-In ribbons at RT. The supercooling of melt spinning technique considerably suppresses the ordering transition and partially retains the low atomic order state (B2 structure) to RT phase of as-spun ribbons. Being subjected to heat treatment, the $\mathrm{L} 2{ }_{1}$ structure is observed in ribbons. On the other hand, in the QW1000 K and $1100 \mathrm{~K}$ samples, the vanishing of (111) peak agreed with the in situ XRD results. The disordered atomic state of as-spun ribbons is preserved and may be even further evolved by the thermal effect.

Table 1. $\mathrm{L} 2{ }_{1}$ atomic order parameters obtained from in situ XRD (X-ray diffraction) analysis.

\begin{tabular}{cccccc}
\hline Temperature & $700 \mathrm{~K}$ & $800 \mathrm{~K}$ & $900 \mathrm{~K}$ & $\mathbf{1 0 0 0} \mathrm{K}$ & $\mathbf{1 1 0 0} \mathrm{K}$ \\
\hline $\begin{array}{c}\text { Atomic order } \\
\text { parameter }\end{array}$ & 0.62 & 0.84 & 0.88 & - & - \\
\hline
\end{tabular}

\subsection{Domains Evolution}

Figure 2 shows the dark-field TEM images taken from Ni-(Co)-Mn-In ribbons, and the inset of each image is the corresponding SAD along (110) zone axis of the bright domains in the image, which are referred to $\mathrm{L} 21$ domains. As-spun ribbons show very weak (111) superlattice reflection (inset of Figure $2 \mathrm{a}$ ), with the small $\mathrm{L} 2_{1}$ domains which are dispersedly distributed in observed regions (Figure 2a). The mixture of B2 and L2 1 regions of as-spun ribbons explains that it is difficult to completely inhibit ordering transition during the rapid quenching and small $\mathrm{L} 2{ }_{1}$ domains induced. While the samples are heated up to the temperature at which the atomic diffusion becomes stronger, the disordered state is modified [22]. However, the $\mathrm{L}_{1}$ domains' morphology of QW700 K samples is roughly the same as those of as-spun ribbons (Figure 2a,b). This suggests that heat activation at $700 \mathrm{~K}$ is weak, which cannot satisfy the diffusion activation energy, and has less effect on modifying the ordering domains. The size of $\mathrm{L}_{1}$ domains increases with quenched temperature between $700 \mathrm{~K}$ and $900 \mathrm{~K}$ (Figure $2 \mathrm{~b}-\mathrm{d}$ ). Thus, the increased atomic order parameter of $\mathrm{S}_{\mathrm{L} 21}$ in in situ heating process is related to the variation of $\mathrm{L} 2{ }_{1}$ domains with increasing quenched temperature below $T_{t}^{B 2 / L 2_{1}}(950 \mathrm{~K})$. Quenching above $T_{t}^{B 2 / L 2_{1}}$, i.e., at $1000 \mathrm{~K}$ and $1100 \mathrm{~K}$, tends to preserve the $\mathrm{B} 2$ regions and significantly inhibit the formation of $\mathrm{L} 21$ domains. Consequently, dispersive small L2 1 domains are shown in QW1000 and $1100 \mathrm{~K}$ ribbons (Figure 2e,f), which represent a comparatively low degree of atomic order. On the contrary, the ordering transition takes place during the slow cooling process (related with $\mathrm{FC}$ ribbons) and $\mathrm{L} 22_{1}$ domains grow further. Therefore, the volume fraction of $\mathrm{L} 2_{1}$ domains increases with the increased annealed temperature, as shown in Figure 2g,k. Comparing the microstructure of ribbons with annealing followed by quenching in water $(\mathrm{QW})$ or furnace cooling (FC), the atomic order domains are also different due to the difference in 
atomic diffusion during cooling, especially for the ribbons heating at $1000 \mathrm{~K}$ and $1100 \mathrm{~K}$. The $\mathrm{L}_{1}$ domains of FC1000 K and FC1100 K ribbons are larger than those of the QW1000 K and QW1100 K ribbons, respectively. This is because the atomic diffusion rate of furnace cooling is larger than that of quenching in water, and the low degree of order in higher temperature is maintained by quenching [23,24]. In addition, the insets in Figure 2 are the selected area electron diffraction along [110] zone axis in the L $2_{1}$ domain of each image. Similarly, domain morphology changes and (111) superlattice diffraction have also been reported by N.M. Bruno et al. in which the domain size changes with the increase in annealing time [17].

(a)

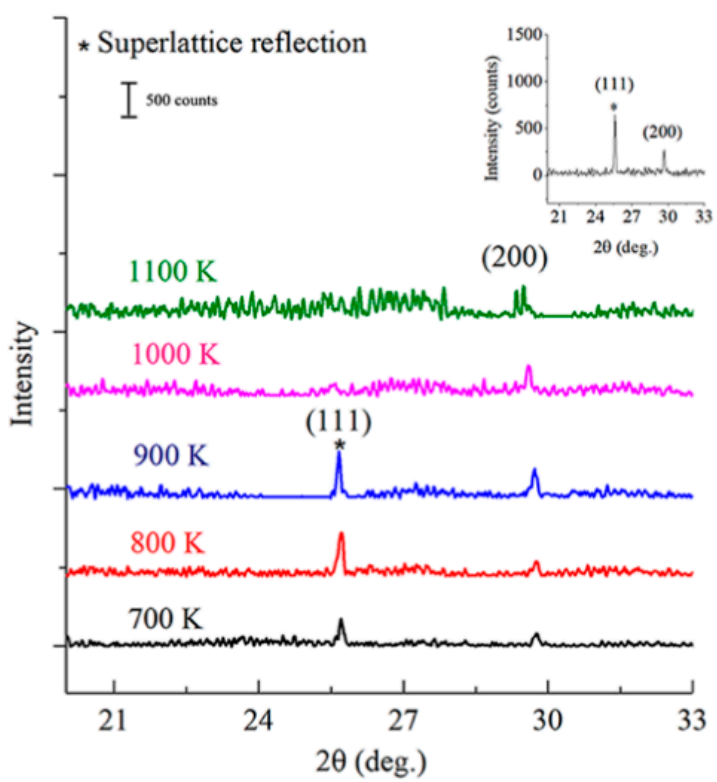

(c)

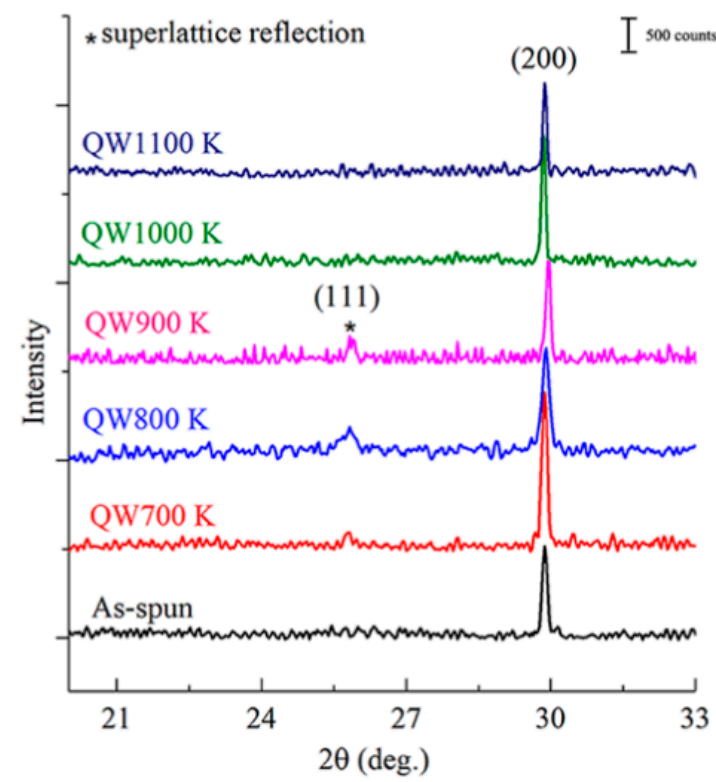

(b)

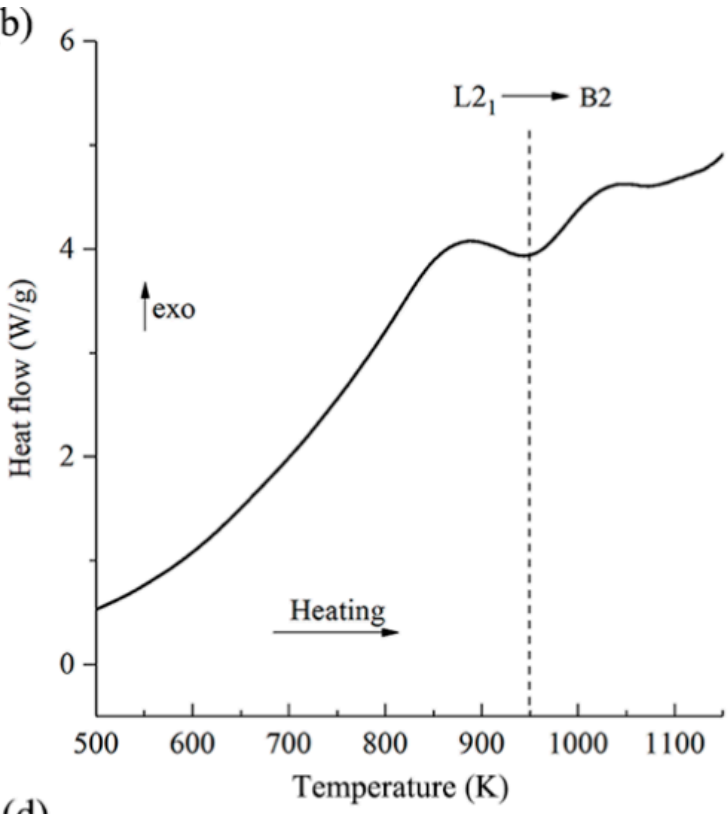

(d)

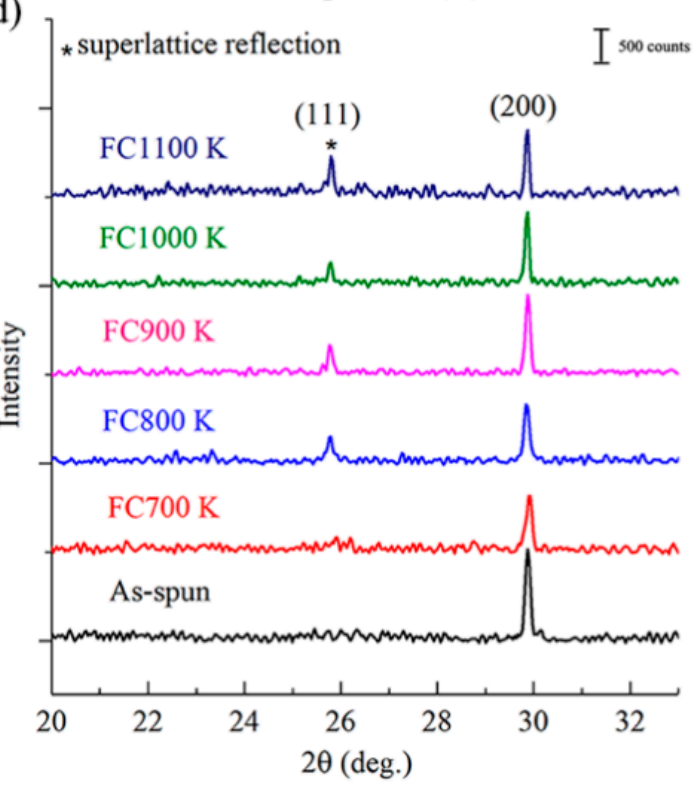

Figure 1. (a) (111) reflections of in situ heating powder XRD (X-ray diffraction) analysis. The inset is the (111) reflection of long-time annealed $\mathrm{Ni}_{45} \mathrm{Co}_{5} \mathrm{Mn}_{36.6} \mathrm{In}_{13.4}$ ribbons. (b) DSC (Differential Scanning Calorimetry) heating curves of $\mathrm{Ni}_{45} \mathrm{Co}_{5} \mathrm{Mn}_{36.6} \mathrm{In}_{13.4}$ ribbons and the transition temperatures were determined by tangent method on the endothermic peak. (c) (111) reflections of XRD analysis of as-spun and QW (ice-water quenching) $\mathrm{Ni}_{45} \mathrm{Co}_{5} \mathrm{Mn}_{36.6} \mathrm{In}_{13.4}$ ribbons and (d) that of as-spun and $\mathrm{FC}$ (furnace cooling) $\mathrm{Ni}_{45} \mathrm{Co}_{5} \mathrm{Mn}_{36.6} \mathrm{In}_{13.4}$ ribbons. 

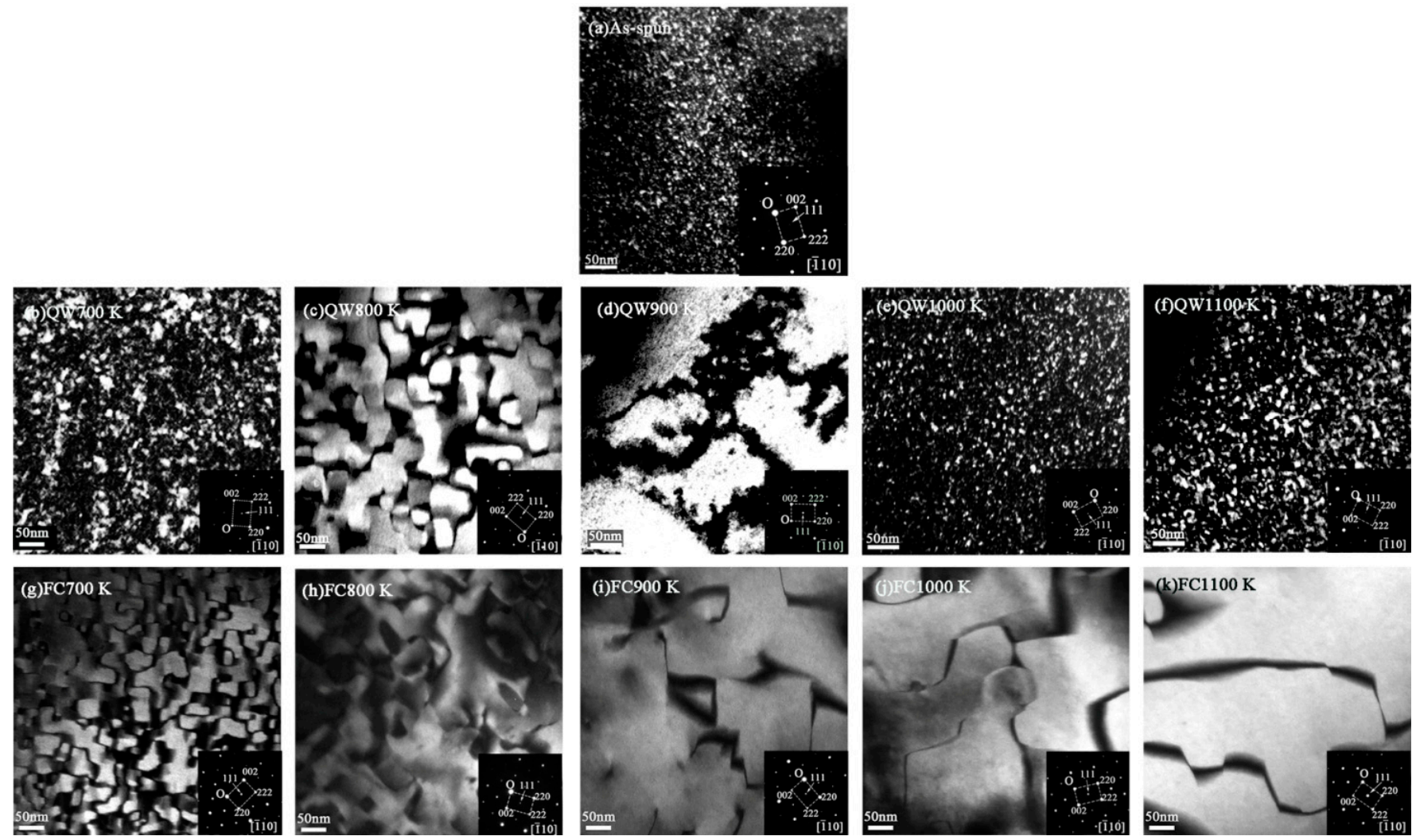

Figure 2. The dark-field images using (111) reflection taken from $\mathrm{Ni}_{45} \mathrm{Co}_{5} \mathrm{Mn}_{36.6} \mathrm{In}_{13.4}$ ribbons for (a) as-spun, quenched at (b) $700 \mathrm{~K}$, (c) $800 \mathrm{~K}$, (d) $900 \mathrm{~K}$, (e) $1000 \mathrm{~K}$ and (f) $1100 \mathrm{~K}$; and annealed at (g) $700 \mathrm{~K}$, (h) $800 \mathrm{~K}$, (i) $900 \mathrm{~K}$, (j) $1000 \mathrm{~K}$ and (k) $1100 \mathrm{~K}$, respectively. Inset of each of image is the corresponding SAD patterns along (110) zone axis of the bright domains in the dark field image.

\section{Conclusions}

The atomic order and ordering domains morphology were analyzed as a function of annealed temperature and cooling rates, and the results are as follows:

1. The evolution of atomic order is attributed to the atomic diffusion occurred in APB, revealed by $\mathrm{L} 2{ }_{1}$ domains' morphology. In situ XRD results indicate that the intensity of (111) reflection is related to the degree of order, which is in accordance with the SAD results.

2. Due to the rapid quenching process, the as-spun ribbons possess B2 structures with small L2 1 domains dispersedly distributed in it. Quenching above $T_{t}^{B 2 / L 2_{1}}$ prevents the formation of $\mathrm{L} 21$ domains and form the $\mathrm{B} 2$ structure with a lower degree of order. On the other hand, when annealing at temperatures below $T_{t}^{B 2 / L 2_{1}}$ followed with quenching, large $\mathrm{L} 2{ }_{1}$ domains are observed, and the size of the domains increases with the increase in temperature.

3. The evolution of L2 1 domains' morphology has a strong dependence on the cooling rates. Atomic order can be further modified during slow cooling process. Ribbons heating at temperatures higher than $T_{t}^{B 2 / L 2_{1}}$ with furnace cooling or quenching in water demonstrate different microstructure as observed by TEM. Low cooling rates greatly promote the formation of $\mathrm{L} 2_{1}$ domains with higher degree of order.

4. The martensitic transformation of Ni-Mn-In alloy depends on its degree of order. Different from other shape memory alloys, B2 structure is better for the martensitic transformation. Therefore, the effect of heat treatment on atomic number discussed above provides a reference to the investigation of Ni-Mn-In alloys series. 
Author Contributions: Conceptualization and methodology, Y.F. and X.W.; TEM observation and analyzation, X.B. and Y.A.; material preparation, H.W. All authors have read and agreed to the published version of the manuscript.

Funding: This work was financially supported by the National Natural Science Foundation of China (No. 51871181 and 51301134) and Zhejiang Provincial Natural Science Foundation of China (No.LY15E010001), as well as the Key Research and Development Program of ShaanXi Province (No.2021GY-344).

Institutional Review Board Statement: Not applicable.

Informed Consent Statement: Not applicable.

Data Availability Statement: The data presented in this study are available from the corresponding author upon request.

Conflicts of Interest: The authors declare no conflict of interest.

\section{References}

1. Sutou, Y.; Imano, Y.; Koeda, N.; Omori, T.; Kainuma, R.; Ishida, K.; Oikawa, K. Magnetic and martensitic transformations of NiMnX (X = In, Sn, Sb) ferromagnetic shape memory alloys. Appl. Phys. Lett. 2004, 85, 4358-4360. [CrossRef]

2. Sánchez-Alarcos, V.; Pérez-Landazábal, J.I.; Recarte, V.; Lucia, I.; Vélez, J.; Rodríguez-Velamazán, J.A. Effect of high-temperature quenching on the magnetostructural transformations and the long-range atomic order of Ni-Mn-Sn and Ni-Mn-Sb metamagnetic shape memory alloys. Acta Mater. 2013, 61, 4676-4682. [CrossRef]

3. Pathak, A.K.; Khan, M.; Dubenko, I.; Stadler, S.; Ali, N. Large magnetic entropy change in $\mathrm{Ni}_{50} \mathrm{Mn}_{50-\mathrm{x}} \mathrm{In}_{\mathrm{x}} \mathrm{Heusler}_{\mathrm{llloys}}$ Appl. Phys. Lett. 2007, 90, 104414. [CrossRef]

4. Koyama, K.; Okada, H.; Watanabe, K.; Kanomata, T.; Kainuma, R.; Ito, W.; Oikawa, K.; Ishida, K. Observation of large magnetoresistance of magnetic Heusler alloy $\mathrm{Ni}_{50} \mathrm{Mn}_{36} \mathrm{Sn}_{14}$ in high magnetic fields. Appl. Phys. Lett. 2006, 89, 182510. [CrossRef]

5. Liu, J.; You, X.M.; Huang, B.W.; Batashev, I.; Maschek, M.; Gong, Y.Y.; Miao, X.F.; Xu, F.; Dijk, N.; Brück, E. Reversible low-field magnetocaloric effect in Ni-Mn-In-based Heusler alloys. Phys. Rev. Mater. 2019, 3, 084409. [CrossRef]

6. Dubenko, I.; Quetz, A.; Pandey, S.; Aryal, A.; Eubank, M.; Rodionov, I.; Prudnikov, V.; Granovsky, A.; Lahderanta, E.; Samanta, T.; et al. Multifunctional properties related to magnetostructural transitions in ternary and quaternary Heusler alloys. J. Magn. Magn. Mater. 2015, 383, 186-189. [CrossRef]

7. Kainuma, R.; Imano, Y.; Ito, W.; Sutou, Y.; Morito, H.; Okamoto, S.; Kitakami, O.; Oikawa, K.; Fujita, A.; Kanomata, T.; et al. Magnetic-field-induced shape recovery by reverse phase transformation. Nature 2006, 439, 957-960. [CrossRef]

8. Sánchez-Alarcos, V.; Recarte, V.; Pérez-Landazábal, J.; Cesari, E.; Rodríguez-Velamazán, J. Long-range atomic order and entropy change at the martensitic transformation in a Ni-Mn-In-Co metamagnetic shape memory alloy. Entropy 2014, 16, $2756-2767$. [CrossRef]

9. Kustov, S.; Corró, M.L.; Pons, J.; Cesari, E. Entropy change and effect of magnetic field on martensitic transformation in a metamagnetic Ni-Co-Mn-In shape memory alloy. Appl. Phys. Lett. 2009, 94, 191901. [CrossRef]

10. Takamura, Y.; Nakane, R.; Sugahara, S. Analysis of $\mathrm{L} 22_{1}$-ordering in full-Heusler $\mathrm{Co}_{2} \mathrm{FeSi}$ alloy thin films formed by rapid thermal annealing. J. Appl. Phys. 2009, 105, 07B109. [CrossRef]

11. Graf, T.; Casper, F.; Winterlik, J.; Balke, B.; Fecher, G.H.; Felser, C. Crystal structure of new heuslercompounds. Z. Anorg. Allg. Chem. 2009, 635, 976-981. [CrossRef]

12. Recarte, V.; Pérez-Landazábal, J.I.; Sánchez-Alarcos, V.; Rodríguez-Velamazán, J.A. Dependenceof the martensitic transformation and magnetic transition on the atomic order in Ni-Mn-In metamagnetic shape memory alloys. Acta Mater. 2012, 60, $1937-1945$. [CrossRef]

13. Bakker, Z.H.; Yang, H. Mechanically driven disorder and phase transformation in alloys. Prog. Mater. Sci. 1995, 39, 159-241. [CrossRef]

14. Yano, T.; Murakami, Y.; Kainuma, R.; Shindo, D. Interaction between magnetic domain walls and antiphase boundaries in $\mathrm{Ni}_{2} \mathrm{Mn}(\mathrm{Al}, \mathrm{Ga})$ studied by electron holography and Lorentz microscopy. Mater. Trans. 2007, 48, 2636-2641. [CrossRef]

15. Ricolleau, C.; Loiseau, A.; Ducastelle, F.; Caudron, R. Logarithmic divergence of the antiphase boundary width in Cu-Pd (17\%). Phys. Rev. Lett. 1992, 68, 3591-3594. [CrossRef]

16. Murakami, Y.; Yanagisawa, K.; Niitsu, K.; Park, H.S.; Matsuda, T.; Kainuma, R.; Shindo, D.; Tonomura, A. Determination of magnetic flux density at the nanometer-scale antiphase boundary in Heusler alloy $\mathrm{Ni}_{50} \mathrm{Mn}_{25} \mathrm{Al}_{12.5} \mathrm{Ga}_{12.5}$. Acta Mater. 2013, 61, 2095-2101. [CrossRef]

17. Bruno, N.M.; Salas, D.; Wang, S.; Roshchin, I.V.; Santamarta, R.; Arroyave, R.; Duong, T.; Chumlyakov, Y.I.; Karama, I. On the microstructural origins of martensitic transformation arrest in a NiCoMnIn magnetic shape memory alloy. Acta Mater. 2018, 142, 95-106. [CrossRef] 
18. Sivaprakash, P.; Arumugam, S.; Muthu, S.E.; Kuma, D.M.; Saravanan, C.; Rama, N.V.; Uwatoko, Y.; Thiyagarajan, R. Correlation of magnetocaloric effect through magnetic and electrical resistivity on Si doped Ni-Mn-In Heusler melt spun ribbon. Intermetallics 2021, 137, 107285. [CrossRef]

19. Liu, J.; Liao, Z.; Xu, F.; Tan, W. Effect of atomic order on the phase transitions of melt-spun $\mathrm{Ni}_{50} \mathrm{Mn}_{35} \mathrm{In}_{15}$ ribbons. Phys. Status Solidi B 2015, 252, 1350-1354. [CrossRef]

20. Wu, D.; Xue, S.; Frenzel, J.; Eggeler, G.; Zhai, Q.; Zheng, H. Atomic ordering effect in $\mathrm{Ni}_{50} \mathrm{Mn}_{37} \mathrm{Sn}_{13}$ magnetocaloric ribbons. Mater. Sci. Eng. A 2012, 534, 568-572. [CrossRef]

21. Miyamoto, T.; Ito, W.; Umetsu, R.Y.; Kainuma, R.; Kanomata, T.; Ishida, K. Phase stability and magnetic properties of $\mathrm{Ni}_{50} \mathrm{Mn}_{50-\mathrm{x}} \mathrm{In}_{\mathrm{x}}$ Heusler-type alloys. Scr. Mater. 2010, 62, 151-154. [CrossRef]

22. Sánchez-Alarcos, V.; Pérez-Landazábal, J.I.; Recarte, V.; Rodríguez-Velamazán, J.A.; Chernenko, V.A. Effect of atomic order on the martensitic and magnetic transformations in Ni-Mn-Ga ferromagnetic shape memory alloys. J. Phys. Condens. Matter 2010, 22, 166001. [CrossRef] [PubMed]

23. Rest, C.; Schmitz, A.; Jacques, P.J. On the characterisation of antisite defects and ordering in off-stoichiometric Fe 2 VAl-based Heusler compounds by X-ray anomalous diffraction. Acta Mater. 2018, 142, 193-200. [CrossRef]

24. Sánchez Llamazares, J.L.; Flores-Zuñiga, H.; Sánchez-Valdes, C.; Ross, C.A.; García, C. Refrigerant capacity of austenite in as-quenched and annealed $\mathrm{Ni}_{51.1} \mathrm{Mn}_{31.2} \mathrm{In}_{17.7}$ melt spun ribbons. J. Appl. Phys. 2012, 111, 07A93. [CrossRef] 